\title{
FAMILIAL ATAXIA-TELANGIECTASIA
}

\author{
BY \\ J. D. PICKUP and R. J. PUGH \\ From the General Infirmary, Pontefract, and the Victoria Hospital for Sick Children, Hull
}

(RECEIVED FOR PUblCATION AUGUST 11, 1960)

A familial syndrome of progressive cerebellar ataxia and choreoathetosis, associated with oculocutaneous telangiectasia and recurrent sinobronchitis in childhood, has recently been described in the American literature. The close similarity of the clinical features observed by Boder and Sedgwick $(1957,1958)$, Wells and Shy (1957), Biedmond (1957), Centerwall and Miller (1958) and Ford (1960) leave no doubt that this represents a new clinical entity to which the two brothers reported here belong. Credit for the first published description belongs to Mme. Louis-Bar (1941).

\section{Case Reports}

David and Barry are the only children of a nonconsanguinous union. Their parents, who are divorced, are both in good health and the father has a normal infant daughter by a second marriage.

David. Born on February 22, 1944, and now aged 16 years, David thrived without causing anxiety during infancy. He weighed $6 \mathrm{lb} .6 \mathrm{oz}$. at birth. Delivery was uncomplicated by injury or anoxia and there was no neonatal jaundice. Locomotor development was at first reassuring with independent walking achieved by 13 months, but from the age of 2 years he gradually became awkward and unsteady, particularly when tired. He lurched unexpectedly, threw out his legs wildly when hurrying and developed irregular movements in the arms. About this time his parents also became aware of a periodic hesitancy in speech and both commented upon the 'blood shot' appearance of his eyes, particularly when excited. Facial grimaces, shaking of the head and drooling of saliva were all prominent by the age of $4 \frac{1}{2}$ years when he first attended the paediatric clinic and his demeanour then suggested athetoid cerebral palsy.

In other fields of attainment David made slow progress. He was fully continent and could feed himself by the age of 3 years and was talking in sentences a year later. At his local school he gave an impression of understanding what was required of him, but found writing increasingly difficult, and talked explosively and indistinctly. His teacher reported that he was 'intelligent', but had little control over his features or limbs. Intelligence testing with the Terman Merrill scale at the age of 8 years gave an Intelligence Quotient of 85 , which on retesting three years later had fallen to 65 . At 13 years David moved from his day school to a residential school for cerebral palsied children, which he has now ${ }_{\perp}$ left to begin attendance at a local occupation centre.

Clinical Features. When first examined by one of us (J.D.P., July 2, 1952) the generalized writhing and jerking of his limbs and facial muscles resembled choreoathetosis. The slurred indistinct speech, drooling of saliva and the irrelevant screwing up of his features gave a false impression of inattention. His injected eyes on close inspection showed telangiectasia of the conjunctivae and ciliary muscles, but were otherwise normal. Walking was propulsive and unsteady, while fine movements of the hands were poorly co-ordinated and laboured. There was no nystagmus and no intention tremor on finger nose testing. The deep reflexes were present but depressed and the superficial reflexes were normal.

Progress. During the ensuing seven years David has gradually deteriorated with progressive ataxia and repeated respiratory infections. By the age of 15 years he was unable to walk unaided and now requires firm support when seated to avoid slipping off a chair. The choreo-athetotic movements continue unceasingly, with writhing of the face, neck, trunk and limbs punctuated irregularly by lunging and jerking. These movements stop during sleep and are reduced by voluntary effort, but make all fine movements laborious in the extreme. David can usually dress himself completely, but he requires nearly an hour to do so, while his signature which is still legible, occupies several minutes of concentrated effort. He feeds himself, is fully continent and can move about in a self-propelling wheel chair. His speech is now too laboured to support a conversation, but remains intelligible. For several years nasal obstruction, drooling of saliva, and irregularity of respiration have been conspicuous. It seems that incoordination of swallowing and breathing contributes to his repeated episodes of lower respiratory infection.

The ocular telangiectasis remains prominent and recently cutaneous lesions including raised pigmented patches (Fig. 1), vesicles and spider naevi have appeared over the face, arm flexures and trunk.

Investigations have been generally uninformative: Blood group $\mathrm{A}, \mathrm{Rh}$ positive, $\mathrm{CDe} / \mathrm{CDe}$; Wassermann and Kahn reactions negative; liver function tests normal; serum protein electrophoresis normal; urine chromatography normal; copper metabolic studies normal. 


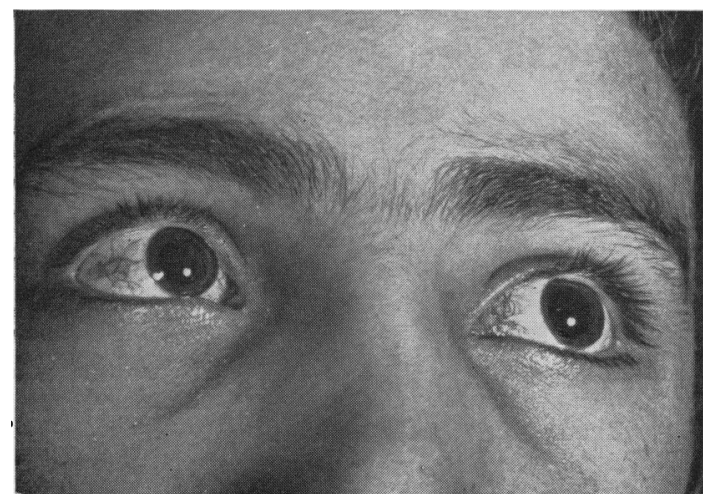

FIG. 1.-David: Close-up view, showing telangiectasia of the eyes and pigmentation of the face.

Barry. Born on July 15, 1948, and now aged 12 years, he was premature, weighing $5.0 \mathrm{lb}$. He thrived in early infancy and occasioned no anxiety until late in the first year when his eyes were appreciably injected. He sat at 9 months, crawled at 11 months, and was walking independently soon after 1 year of age. He began to use words at 15 months and to converse by the age of 2 years. The close resemblance to his brother was emphasized when irregularities of hand movements and gait appeared at about $\mathbf{3}$ years of age. In retrospect Barry's progress has been very similar to that of David, with gross choreoathetosis and ataxia evident by 5 years and the degree of incapacity remaining compatible with attendance at ordinary school until the 11th year. Recently Barry has been unable to play freely out of doors or to travel by public transport unaccompanied. $\mathrm{He}$ is awaiting admission to a residential school for cerebral palsied children.

Ophthalmological examination when 5 years old showed well-marked dilatation of the conjunctival ciliary vessels in both eyes and the underlying sclera appeared unusually transparent. His speech by then was slurred and precipitate.

An intelligence test at the age of 8 years gave an I.Q. of 85 , but at the age of 10 years he could only read the simplest words and had mastered only the 2 times multiplication table. Observed alongside his brother, Barry shows the same range of involuntary movements, affecting his face and extremities in particular, but not to the same degree. In both, these movements are a combination of continuous writhing interrupted by irregular jerking. He is able to sit more erect than David, to walk unaided but with marked ataxia and with feet placed well apart, and his speech is more audible. Both their mother and maternal grandfather agree, however, that the two boys are equally severely affected, making due allowance for the differences in ages.

Neurological examination shows generalized hypotonia with depressed deep reflexes and normal abdominal and plantar responses. There is nystagmus on looking laterally and loss of balance standing when the eyes are closed. Hand movements are laboured and ataxic

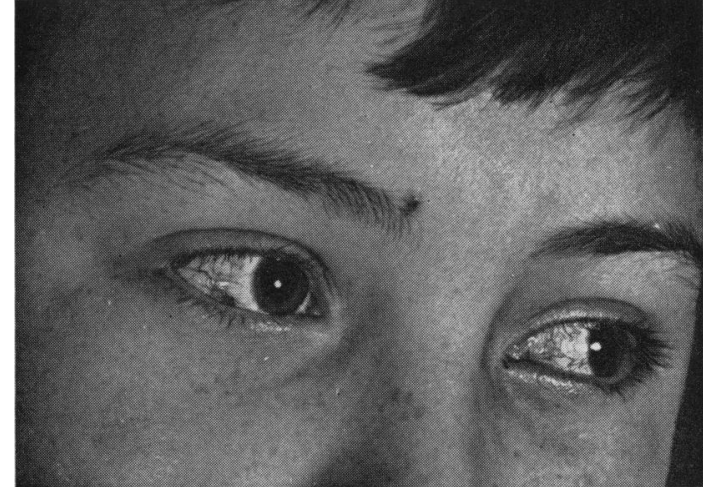

FIG. 2.-Barry: Close-up view, showing telangiectasia of the eyes and pigmentation of the face.

but without any fine intention tremor. Barry can feed, wash and dress himself and he is fully continent. Writing is achieved only with great effort. Breathing is noisy and irregular, and swallowing incoordinate, allowing saliva to ruckle in the throat and to trickle out of the mouth. He shows ocular telangiectasis and café au lait patches over the skin (Fig. 2), but no cutaneous telangiectasia; however, the nasal mucosa is swollen and nasal congestion always troublesome. Acute lower respiratory infections occur regularly during the winter months.

Investigations have not brought to light any abnormal clinical pathology: Blood group $\mathrm{O}$, $\mathrm{Rh}$ positive, $\mathrm{CDc} / \mathrm{CDc}$; Wassermann and Kahn reactions negative; liver function tests normal; electrophoresis of plasma proteins normal; urine chromatography normal; a skull radiograph shows no calcification; cerebrospinal fluid examination shows no abnormality.

\section{Discussion}

The outstanding feature of this rare syndrome is the combination of conspicuous ocular telangiectasia with progressive cerebellar ataxia in early childhood. A superficial resemblance to athetoid cerebral palsy is dispelled by the progressive character of the involuntary movements and the development of a true ataxia. Cutaneous telangiectasia most commonly involving the cheeks, the nasal bridge, the external ears, the neck root and the skin over bony prominences, when fully manifest provides the very characteristic clinical picture illustrated by Centerwall and Miller (1958). Café au lait pigmentation of varying degree present in Mme. Louis-Bar's case was noted by Boder and Sedgwick (1957), and is evident on the face in both the children reported here.

Associated respiratory symptoms present with progressive nasal congestion and mouth breathing. Drooling is regularly troublesome and recurrent acute lower respiratory infections probably result 
from the increasing incoordination of swallowing and breathing so that much naso-pharyngeal secretion is inspired.

Autopsy findings are reported by Boder and Sedgwick (1958) and Centerwall and Miller (1958) both of whom found neuronal degeneration maximal in the cerebellum and associated with enlarged venules in the cerebellar leptomeninges and in the white matter of the cerebellum.

\section{Summary}

An account is given of two brothers in whom progressive cerebellar ataxia is associated with telangiectasia of the conjunctivae and more recently of the skin. Progressively severe sinobronchitis completes the clinical entity of ataxia-telangiectasia which has only recently been described.
Acknowledgement is gratefully made to Dr. Dixon who attended David in a Bolton residential school.

\section{REFERENCES}

Biedmond, A. (1957). Paleocerebellar atrophy with extrapyramidal manifestations in association with bronchiectasis and telangiectasis of the conjunctiva bulbi as a familial syndrome. First International Congress of Neurological Sciences, Brussels, July 21-28, 1957.

Boder E. and Sedgwick, R. P. (1957). Ataxia-telangiectasia: a familial syndrome of progressive cerebellar ataxia, oculocutaneous telangiectasia and frequent pulmonary infection. Univ. South Calif. Med. Bull., 9, 15.

- (1958). Ataxia-telangiectasia. A familial syndrome of progressive cerebellar ataxia, oculocutaneous telangiectasia and frequent pulmonary infection. Pediatrics, 21, 526

Centerwall, W. R. and Miller, M. M. (1958). Ataxia, telangiectasia and sinopulmonary infections. A syndrome of slowly progressive and sinopulmonaryinfections. A syndrome of slowly progressive

Ford, F. R. (1960). Diseases of the Nervous System, 4th ed., p. 944. Blackwell, Oxford.

Louis-Bar (1941). Sur un syndrome progressif comprenant des télangiectasies capillaires cutanées et conjonctivales symétriques. à disposition naevoìde et des troubles cérébelleux. Confin. neurol. (Basel), 4, 32.

Wells, C. E. and Shy, G. M. (1957). Progressive familial choreoathetosis with cutaneous telangiectasia. J. Neurol. Neurosurg. Psychiat., 20, 98. 